\title{
Gas-Liquid Churn Flow: Interfacial Wave and Drop Entrainment
}

\author{
BoFeng Bai \\ State Key Laboratory of Multiphase Flow in Power Engineering \\ $\mathrm{Xi}$ 'an Jiaotong University \\ Xi'an, 710049, China \\ Bfbai@mail.xjtu.edu.cn
}

Churn flow is one of the least understood gas-liquid flow regimes due to its complexity and there have been enduring efforts to define it. Generally, churn flow is considered as an intermediate flow regime between slug flow and annular flow and occurs after the break-down of slug flow as its gas flow velocity increases. For it frequently occurs in power engineering, chemical engineering and other industrial application, churn flow has a significant influence on the safety and management control. Depth knowledge of the huge-wave properties and drop entrainment mechanism is crucial to provide better understanding of churn flow. In this talk, the feature of churn flow and up-to-date study were concluded firstly. Then, the experimental method was introduced to reconstruct the gas-liquid churn flow visually and be able to measure the huge wave movement and the drop entrainment. Based on the experimental results, the huge wave profile and its behavior were proposed, and new mechanism of the droplet entrainment under great gas flow velocity was revealed. We also established analytical models to study the huge wave movement and drop entrainment, respectively. In the end, the physical mechanisms and mathematical models were employed to predict the critical heat flux in the boiling flow. 